\title{
ESTILOS PARENTAIS, SATISFAÇÃO CONJUGAL E AJUSTAMENTO DIÁDICO: UM ESTUDO EXPLORATÓRIO
}

\author{
Antoniela Yara Marques da Silva Dias \\ UFPR/FACEL \\ aymds@yahoo.com.br \\ Lidia Natalia Dobrianskyj Weber \\ UFPR \\ lidia@lidiaweber.com.br
}

Fecha de Recepción: 8 Abril 2018

Fecha de Admisión: 10 Abril 2018

\section{RESUMO}

Esta pesquisa objetivou investigar relações entre estilos parentais percebidos, a satisfação conjugal e o ajustamento diádico. 157 participantes responderam os seguintes instrumentos: Escala de Satisfação conjugal, Escala de Estilos Parentais (e Escala de Ajustamento Diádico. Os participantes eram casais que se declarassem casados (legalmente ou não). Os principais dados referentes à exigência e responsividade dos pais e aos estilos parentais revelam que os participantes que mais perceberam seus pais como exigentes $(r=0,20, p<0,05)$ e responsivos $(r=0,19, p<0,05)$ eram os casais mais coesos; os participantes que perceberam seus pais com estilo negligente tiveram médias mais baixas na Escala de Ajustamento Diádico $(F=2,455, p<0,05)$. Com relação à satisfação conjugal, os principais resultados mostram que os participantes que perceberam seus pais como negligentes apresentaram baixa satisfação conjugal e os que perceberam seus pais como autoritativos apresentaram elevada satisfação conjugal $\left(c^{2}=27,947 ; p<0,01\right)$. Os participantes mais diadicamente ajustados $\left(c^{2}=54,752 ; p<0,01\right)$ também foram aqueles que apresentaram elevada satisfação conjugal. Pôde-se concluir com tais dados a possível influência do estilo parental percebido pelos participantes no relacionamento do casal, na satisfação conjugal e no ajustamento diádico, bem como as claras correlações entre aspectos do ajustamento e da satisfação do casal, isto é, quanto mais ajustados os cônjuges, também mais satisfeitos.

Palavras-chave: estilos parentais; satisfação conjugal; ajustamento diádico

\section{ABSTRACT}

Parenting styles, marital satisfaction and dyadic adjustment: an exploratory study.

This research intended to investigate possible relations among the perceived parental styles, marital satisfaction and dyadic adjustment. Altogether, 157 participants answered the following 


\section{ESTILOS PARENTAIS, SATISFAÇÃO CONJUGAL E AJUSTAMENTO DIÁDICO: UM ESTUDO EXPLORATÓRIO}

instruments: Marital Satisfaction Scale, Parenting styles Scale and the Dyadic Adjustment Sscale. The participants were couples who declared themselves married (legally or not). The main data regarding the parents' demanding and responsiveness and the parental styles reveal that the participants who perceived their parents as demanding $(r=0,20, p<0,05)$ and responsiveness $(r=0,19$, $p<0,05)$ the most were the more cohesive couples and, the participants who perceived their parents (father and mother combined) with a more uninvolved style exhibited a low rate of marital satisfaction and the ones who perceived their parents as authoritative exhibited a high rate of marital satisfaction ( $\left.c^{2}=27,947 \mathrm{gl}=6, p<0,01\right)$. The more dyadically adjusted couples $\left(c^{2}=54,752, g l=2, p<0,01\right)$ were also the ones who exhibited a high rate of marital satisfaction. It was possible to conclude with such data the possible influence of the marital style perceived by the participants in the couple's relationship, in the marital satisfaction and in the dyadic adjustment, as well as the clear correlations between aspects of the adjustment and the couple's satisfaction, that is, the more adjusted the partners, the more satisfied. However, the data raise multiple questions to be answered indicating the relevance of the studies on the topic.

Keywords: parenting styles; marital satisfaction; dyadic adjustment

\section{REVISÃO DE LITERATURA}

\section{Estilos Parentais}

Baumrind (1966), a precursora do modelo teórico acerca de práticas educativas parentais, indicou três estilos parentais característicos dos pais, no caso, o permissivo, 0 autoritário e o negligente. Mais tarde, Maccoby e Martin (1983) consolidaram os estudos sobre 0 tema com a proposta de avaliação dos estilos em duas dimensões: responsividade e exigência (Costa, Teixeira e Gomes, 2000). A partir dessas duas dimensões derivam os Estilos Parentais autoritário (alta exigência e baixa responsividade), autoritativo (alta exigência e alta responsividade), negligente (baixa exigência e responsividade) e, por fim, o indulgente/permissivo (alta permissividade, ou seja, alta responsividade e pouca exigência) (Maccoby \& Martin, 1983; Costa, Teixeira e Gomes, 2000).

Muitas pesquisas surgiram a respeito do tema nas últimas décadas. Mondin (2008) afirma que se deve primar pelas práticas educativas positivas em detrimento das práticas negativas, uma vez que tais práticas podem culminar em prejuízo no desenvolvimento infantil. Na mesma direção, Carvalho e Silva (2014) discutem a literatura nacional encontrada e indica que os respondentes de famílias com práticas negativas evidenciaram um repertório de habilidades sociais deficitário em $62 \%$ (estudo de Gomide \& cols., 2005), além do comportamento da mãe predizer competência social, da mesma forma em que a falta de monitoria positiva do pai aumentavam as chances de repertório social infantil deficitário (Salvo, Silvares \& Toni, 2005).

0 estudo de Sapienza, Aznar-Farias e Silvares (2009) mostrou que os adolescentes com alto rendimento acadêmico atingiram médias mais altas em todas as variáveis que mediam a competência social, especialmente no que se referiu às atividades sociais, relacionamento social e no total da competência social. Em relação às práticas parentais, os pais dos adolescentes com alto rendimento acadêmico tiveram escore total positivo mais alto e também escores mais baixos de práticas educativas negativas (disciplina relaxada e abuso físico).

Carneiro e Oliveira relataram que a maior parte dos participantes adultos (38\%) que perceberam seus pais com estilo autoritativo tinha um repertório bastante elaborado de habilidades sociais ou um bom repertório de habilidades sociais (27\%). Em contrapartida, daqueles que perceberam seus pais como autoritários revelaram repertório deficitário de habilidades sociais.

Diante do exposto, pode-se perceber a estreita relação entre os estilos e práticas parentais com 0 desenvolvimento da criança, podendo chegar a ter efeitos na vida adulta e pesquisas revelam que 
jovens com uma vinculacao mais segura aos pais tendem a exibir uma vinculacao mais segura ao par amoroso (por exemplo, Mendonça \& Almeida, 2010).

A seguir será tratado um aspecto vivenciado neste período de desenvolvimento, a saber da relação conjugal. Posteriormente, serão discutidas possíveis relações dos Estilos Parentais com a Satisfação Conjugal.

\section{Satisfação Conjugal e Ajustamento Diádico}

Segundo Scorsolini-Comin e Santos (2011), "a satisfação conjugal é um construto complexo a ser definido. Tal complexidade deve-se ao fato de que ela é composta por diferentes variáveis, desde as características de personalidade dos cônjuges e as experiências que eles trazem das suas famílias de origem até a maneira como eles constroem o relacionamento a dois (p. 54)". Apesar dos autores afirmarem a complexidade do construto, eles o apresentam como um modo subjetivo de um relacionamento amoroso a longo prazo. Scorsolini-Comin e Santos (2012) fazem uma distinção entre a Satisfação Conjugal, uma avaliação que cada parceiro faz do cônjuge, e os domínios da conjugalidade, que têm como foco a avaliação do casal.

Scorsolini-Comin e Santos (2011) investigaram as possíveis relações entre as dimensões da Escala de Ajustamento Diádico e a Escala de Satisfação Conjugal. Foi possível observar correlação significativa da Satisfação com os seguintes domínios da escala: aspectos emocionais, interação conjugal e aspectos estruturais (este foi o único domínio que manteve correlação significativa por meio da análise de regressão múltipla).

Na mesma direção, Scorsolini-Comin e Santos (2012) debateram a utilização da Escala de Ajustamento Diádico para a avaliação da conjugalidade e os fatores da escala correlacionam-se entre si, sendo que as correlações mais significativas foram entre consenso e coesão e consenso e expressão de afeto. Uma correlação negativa foi identificada: satisfação do casal e o consenso. Os autores discutem que, apesar de um casal com elevado consenso apresentar menor índice de conflito, isto não é o mesmo que dizer que se trata de um casal feliz, mas pode indicar a relação entre coesão e consenso do casal. Neste sentido os autores afirmam "pessoas casadas e com coesão no relacionamento tendem a ter maior nível de consenso, mas as casadas que experimentam grande consenso nem sempre são coesas" (p. 5).

Rosado e Wagner (2015) realizaram uma revisão sistemática da literatura visando mapear estudos relacionados à felicidade na relação conjugal. Dentre os estudos que fazem referência ao escopo da presente pesquisa, do eixo "determinantes da qualidade conjugal", pode-se destacar os estudos de Ghimire (2013) e Bertoni e Bondenmann (2010) que indicaram os fatores nível da educação, tempo de duração da relação e idade dos cônjuges positivamente associados à qualidade conjugal. No eixo "intervenção na conjugalidade" aponta-se para a relação entre a baixa autoestima, a insatisfação com o parceiro e problemas na comunicação (Bullard \& cols., 2010; Morrisa, McMilland, Duncanc \& Larson, 2011), bem como a relação entre 0 apoio emocional do cônjuge e a apreciação positiva da relação diádica (Lawrence \& cols., 2008; Stapleton \& cols., 2012). Rosado e Wagner (2015) discutem a falta de consenso em relação à definição do construto de Satisfação Conjugal.

0 objetivo deste trabalho foi investigar possíveis relações entre os Estilos Parentais percebidos, Satisfação Conjugal e Ajustamento Diádico.

\section{MÉTODO}

\section{Participantes:}

fizeram parte desta pesquisa 157 casais heterossexuais casados ou que estivessem morando juntos. 


\section{ESTILOS PARENTAIS, SATISFAÇÃO CONJUGAL E AJUSTAMENTO DIÁDICO: UM ESTUDO EXPLORATÓRIO}

Instrumentos:

Escala de Satisfação conjugal (Dela Coleta, 1989): contém 24 questões, das quais cinco foram retiradas $(1,11,17,20,22)$. As repostas seguem um padrão Likert de três pontos. Este instrumento é dividido em quatro dimensões: satisfação com o seu casamento, satisfação com os aspectos emocionais do cônjuge; satisfação com a interação entre 0 casal e satisfação com a maneira de organização, de estabelecimento e de realização de regras do parceiro.

Escala de Responsividade e Exigência (Lamborn \& cols., 1991): contém 16 questões divididas em duas escalas (exigência e responsividade) para serem respondidas em uma escala de Lickert de três pontos, cujas respostas classificam os estilos parentais (autoritário, autoritativo, negligente e permissivo) de acordo com a percepção dos participantes.

Escala de Ajustamento Diádico (Spanier, 1976): contém 32 questões, das quais foram retiradas quatro $(12,14,15,21)$ para o presente estudo. 0 instrumento deve ser respondido por meio de uma escala de Lickert de seis pontos e, alguns itens, com respostas dicotômicas de "sim" e "não".

\section{Procedimento:}

foram realizados contatos com instituições religiosas que tivessem um trabalho com grupos de casais para arealiacão da pesquisa. 0 contato com os participantes foi feito de maneira direta (abordado pessoalmente) ou indireta (com o auxílio de terceiros) sendo entregues os instrumentos de forma sigilosa (dentro de envelopes lacrados). Todo este processo ocorreu conforme a disponibilidade de cada participante, voluntária, anonimamente e sem a interferência de terceiros (incluindo 0 parceiro). Os participantes assinaram o Termo de consentimento Livre e Esclarecido. Nos casos em que os dados foram coletados em instituições, estas foram contatadas e informadas com antecedência e, após a autorização das instituições, os instrumentos foram aplicados em reuniões de casais.

\section{RESULTADOS E DISCUSSÃO}

A amostra estava praticamente igualmente dividida entre homens (48\%) e mulheres (52\%), a maioria estava casada (84\%) ou moravam junto (16\%). Com relação à idade, $80 \%$ tinha acima de 30 anos. Com relação à religião, a maior parte dos participantes era católica (48\%), 36\% eram evangélicos, 9\% eram espíritas, testemunhas de Jeová e como participantes da religião de Deus e os demais se autodeclararam sem religião $(7 \%)$.

Acerca dos Estilos Parentais percebidos levou-se em conta o pais e a mãe juntos, sendo que 0 estilo predominante foi o negligente $(37 \%)$, seguido do estilo autoritativo $(36 \%), 14 \%$ dos pais foram percebidos como autoritários e 13\% como permissivos.

A Tabela 1 mostra as relações entre escores das dimensões de Ajustamento Diádico e Estilos Parentais percebidos (pai e mãe combinados) analisados pelo teste de variância ANOVA.

Tabela 1: Relações entre escores das dimensões de Ajustamento Diádico e Estilos Parentais percebidos (pai e mãe combinados) por casais e analisados pelo teste de variância ANOVA

\begin{tabular}{|c|c|c|c|c|c|}
\hline EP combinados & Coesão diádica & Satisfação diádica & Consenso diádico & $\begin{array}{c}\text { Expressão } \\
\text { de afeto }\end{array}$ & $\begin{array}{c}\text { Ajustamento diádico } \\
\text { (escore total) }\end{array}$ \\
\hline Permissivo & 26,18 & 24,35 & 60,12 & 8,41 & 119,06 \\
\hline Autoritativo & 26,57 & 24,82 & 59,53 & 8,14 & 119,06 \\
\hline Negligente & $22,29 *$ & $23,55^{*}$ & $54,84 *$ & 7,47 & $107,98 *$ \\
\hline
\end{tabular}

*Diferença estatisticamente significativa $\mathrm{p}<0,05$. 
Considerando a dimensão de coesão diádica ( $F=6,865, p<0,01)$, a satisfação diádica ( $F=3,245$, $p<0,05)$ e 0 escore total da Ajustamento Diádico $(F=2,455, p<0,05)$, a Tabela 1 mostra uma relação estatisticamente significativa entre 0 Estilo Parental Negligente e os escores mais baixos em quatro das cinco dimensões. Este resultado mostra que os participantes que percebem seus pais com baixa responsividade e exigência (característica do estilo negligente) têm mais dificuldade no quesito social, incluindo, neste caso, a relação conjugal.

0 resultado apresentado vai ao encontro da proposta de Darling (1999) ao dizer que crianças e adolescentes cujos pais têm um Estilo Parental Negligente, apresentam repertório empobrecido em todos os domínios. A autora afirma que há relação entre o estilo autoritativo e a competência social e instrumental dos filhos. Da mesma forma, os dados apresentados na Tabela 1 vão ao encontro dos resultados apresentados por Carvalho e Silva (2014) ao discutirem o estudo de Gomide e cols. (2005) e Salvo, Silvares e Toni (2005). No primeiro caso os respondentes de famílias com práticas negativas evidenciaram um repertório de habilidades sociais deficitário em $62 \%$. No segundo caso o estudo mostrou que comportamento da mãe predizia competência social, enquanto que a falta de monitoria positiva do pai aumentava as chances de repertório social infantil deficitário. Em ambos estudos, o repertório deficitário de habilidades sociais esteve relacionado a práticas que podem ocorrer no estilo negligente, ou seja, práticas como essa podem estar relacionadas a dificuldades em interações sociais, culminando em uma dificuldade na interação conjugal.

Assim, pode-se dizer que os estilos parentais adotados pelos pais podem exercer influência sobre 0 comportamento social dos filhos, a qual pode se estender a diversas relações, perpassando, inclusive, a relação conjugal.

A Figura 1 mostra a relação entre a Satisfação Conjugal e o Estilo Parental (pais e mãe juntos) percebido pelos participantes da pesquisa.

Figura 1: Porcentagem dos estilos de pai e mães combinados percebidos pelos casais e categorias de sua Satisfação Conjugal (c2=27, $947 \mathrm{gl}=6, p<0,01)$.

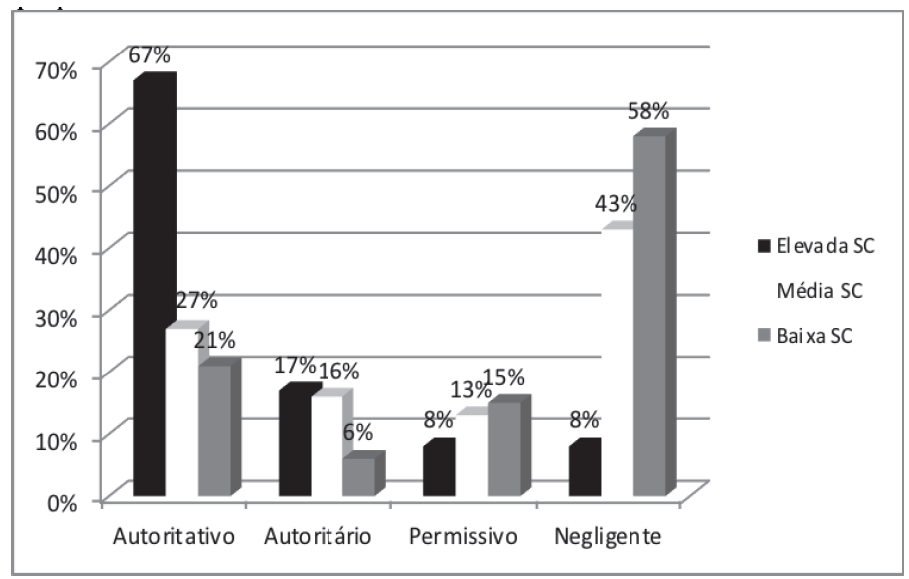

Pela Figura 1 nota-se que um alto percentual de casais que percebe seus pais como negligentes também apresentou baixa e média Satisfação Conjugal. Em contrapartida, os casais que percebem seus pais como autoritativos mostram ter elevada Satisfação Conjugal. A hipótese para tal dado está atrelada ao alto nível de exigência e de responsividade, característicos do estilo autoritativo, ser generalizado da relação parental para a conjugal e, desta forma, o filho que perceber seus pais como 


\section{ESTILOS PARENTAIS, SATISFAÇÃO CONJUGAL E AJUSTAMENTO DIÁDICO: UM ESTUDO EXPLORATÓRIO}

autoritativos tem uma maior chance de agir de forma a imitar o modelo de seus pais para com o seu parceiro.

Darling (1999) menciona que a responsividade prediz competência social e psicossocial e a exigência relaciona-se à competência instrumental e controle do comportamento. Além disso, o estilo autoritativo está relacionado a baixos níveis de problemas comportamentais nos diferentes estágios do desenvolvimento dos filhos. A constatação de Darling, aliada aos dados da presente pesquisa, relacionam-se com o estudo de Sapienza, Aznar-Farias e Silvares (2009), no qual adolescentes que tiveram escores maiores em sua percepção de práticas parentais positivas atingiram médias mais altas em todas as variáveis que mediam a competência social. No caso do presente estudo, inferese que os respondentes que relataram perceber seus pais com estilo autoritativo (melhores práticas) eram aqueles que aprenderam melhores habilidades e competência social.

Outro estudo que corrobora os dados encontrados na presente pesquisa é de Carneiro e Oliveira (2013). Os participantes do estudo que perceberam seus pais com estilo autoritativo apresentavam um bom repertório de habilidades sociais, fato que revela a estreita relação entre os estilos parentais e a habilidade social desenvolvida no filho. Outra pesquisa realizada com estudantes universitários que relataram as práticas educativas de suas mães (Weber \& Ton, 2011), fez uma análise por segmentação e agrupamento de semelhantes (cluster analysis) e encontrou relações estatisticamente significativas entre as práticas educativas parentais e 0 desenvolvimento de habilidades sociais.

Transpondo essas informações para a relação conjugal, pode-se dizer que possivelmente os participantes com elevada Satisfação Conjugal que perceberam seus pais como autoritativos possivelmente aprenderam na relação parental habilidades que são de grande valia em uma relação diádica, ou seja, a competência social e instrumental favorecida pelo estilo parental autoritativo podem ter influenciado diretamente nas habilidades na interação com o parceiro e, por sua vez, na Satisfação Conjugal.

A Tabela 2 apresenta os resultados da Correlação de Pearson entre os escores da Escala de Satisfação Conjugal e os escores da Escala de Ajustamento Diádico.

Tabela 2: Correlação dos escores das dimensões da escala de SC com os escores das dimensões da Escala de Ajustamento Diádico (EAD)

\begin{tabular}{lllcc}
\hline Dimensões da EAD & $\begin{array}{l}\text { Aspectos } \\
\text { emocionais }\end{array}$ & $\begin{array}{l}\text { Interação } \\
\text { conjugal }\end{array}$ & $\begin{array}{c}\text { Organização e } \\
\text { regras }\end{array}$ & $\begin{array}{c}\text { Escore total da } \\
\text { satisfação }\end{array}$ \\
\hline Consenso diádico & $0,47^{* *}$ & $0,68^{* *}$ & $0,65 * *$ & $0,72^{* *}$ \\
Satisfação diádica & $0,17^{*}$ & 0,14 & 0,14 & 0,17 \\
Coesão & $0,39 * *$ & $0,62 * *$ & $0,52^{* *}$ & $0,62^{* *}$ \\
Expressão de afeto & $0,27 * *$ & $0,62^{* *}$ & $0,49 * *$ & $0,57 * *$ \\
Escore total do ajustamento & $0,49 * *$ & $0,74 * *$ & $0,67 * *$ & $0,77^{* *}$ \\
\hline
\end{tabular}

*Correlação tem significância ao nível de $0,05 * *$ Correlação tem significância ao nível de 0,01

A satisfação com os aspectos emocionais do cônjuge, a satisfação com a interação conjugal, bem como com a satisfação com a organização e regras e 0 escore total da Satisfação Conjugal apresentaram forte correlação com o consenso diádico. 0 mesmo aconteceu com a coesão diádica, a expressão de afeto e com 0 escore total de ajustamento diádico. Com relação à satisfação diádica, a única variável que apresentou relação significativa foi a dimensão aspectos emocionais do cônjuge. Os dados apresentados são corroborados pela pesquisa de Scorsolini-Comin e Santos (2011), a qual demonstrou as correlações existentes entre as dimensões do Ajustamento Diádico e Satisfação Conjugal, sugerindo harmonia entre os construtos avaliados pelos instrumentos. 
As correlações apresentadas são evidências interessantes sobre a vida familiar pregressa e 0 relacionamento conjugal, uma vez que, à medida que há mais consenso, coesão e expressão de afeto entre a díade, menor é a probabilidade de conflitos, favorecendo aspectos da satisfação conjugal. Ou seja, quanto mais ajustado o casal, maiores as oportunidades de vivenciarem a relação como satisfatória. Vale destacar, no entanto, que não se pode afirmar a direção da correlação - se os aspectos do ajustamento que determinam a satisfação ou se é a satisfação Ccnjugal que proporciona maior ajustamento.

Sardinha, Falcone e Ferreira (2009) afirmaram que a empatia está relacionada à interação conjugal e à satisfação com os aspectos emocionais do cônjuge, assim como a expressão de sentimentos relaciona-se com a Satisfação Conjugal. Esse resultado caminha na direção do dado encontrado no presente estudo, uma vez que demonstra a influência de diversos fatores relacionados à interação que, por sua vez, exercem influência sobre a Satisfação Conjugal.

A Tabela 3 mostra as relações entre as dimensões da Escala de Ajustamento Diádico com a Satisfação Conjugal, comparados pela análise de variância ANOVA.

Tabela 3: Médias e relações entre os escores das dimensões da Escala de Ajustamento Diádico e as categorias da Satisfação Conjugal analisadas por meio do ANOVA

\begin{tabular}{lccc}
\hline \multicolumn{1}{c}{ Dimensões da EAD } & Elevada SC & Média SC & Baixa SC \\
\hline Coesão diádica & 27,98 & 25,83 & $19,41^{*}$ \\
Satisfação diádica & 25,22 & 24,64 & 23,87 \\
Consenso diádico & $64,59^{*}$ & $58,59 *$ & $48,79^{*}$ \\
Expressão de afeto & 8,85 & 8,18 & $6,51^{*}$ \\
Ajustamento diádico (escore total) & $126,63^{*}$ & $117,20^{*}$ & $98,59^{*}$ \\
\hline
\end{tabular}

*Diferença estatisticamente significativa

Foi possível verificar diferença significativa entre as categorias da Satisfação Conjugal em todas as dimensões da Escala de Ajustamento Diádico, exceto a dimensão de satisfação diádica. Com relação à coesão diádica $(F=38,257, p<0,01)$ o resultado foi significativo apenas para a categoria de baixa Satisfação (com média mais baixa, comparando às outras médias da mesma dimensão). No caso do consenso diádico $(F=56,243, p<0,01)$ a diferença foi significativa para todas as categorias da Satisfação, bem como para o escore total do Ajustamento Diádico ( $F=70,879, p<0,01)$. A dimensão expressão de afeto $(F=29,132, p<0,01)$ mostrou diferença estatisticamente significativa para a baixa Satisfação Conjugal. Estes resultados mostram que os participantes com as médias mais baixas na coesão, consenso, expressão de afeto e ajustamento total se encontram na categoria de "baixa Satisfação Conjugal". Com isso, pode-se afirmar o lugar especial dessas dimensões (coesão, consenso e expressão de afeto) na avaliação dos parceiros em relação a sua Satisfação, ou seja, o quanto a falta de habilidades a elas relacionadas pode implicar numa insatisfação com a relação. Ainda na Tabela 3, a dimensão "consenso diádico" apresentou diferença estatisticamente significativa em todas as categorias. Tal resultado pode indicar uma relação estreita entre a forma como os casais lidam com as negociações (e, assim, com o consenso) e seu efeito na Satisfação global. Segundo Karwowski-Marques (2008) menciona que um determinado grau de consenso é importante para que o nível de insatisfação não fique elevado, para tanto, as negociações e ajustes são imprescindíveis. 


\section{ESTILOS PARENTAIS, SATISFAÇÃO CONJUGAL E AJUSTAMENTO DIÁDICO: UM ESTUDO EXPLORATÓRIO}

Na mesma direção, Scorsolini-Comin e Santos (2012) pesquisaram a utilização da Escala de Ajustamento Diádico para a avaliação da conjugalidade. Os resultados mostraram que as correlações mais significativas foram entre os fatores consenso e coesão e consenso e expressão de afeto. Os autores discutem que, apesar de um casal com elevado consenso apresentar menor índice de conflito, isto não é o mesmo que dizer que se trata de um casal feliz, mas pode indicar a relação entre coesão e consenso do casal. Tal afirmação contradiz o resultado encontrado na presente pesquisa, uma vez que os casais que apresentaram baixa Satisfação Conjugal foram os mesmos que apresentaram menores médias no consenso diádico. Mais pesquisas que envolvam tais variáveis devem ser realizadas, a fim de que sejam melhores esclarecidos os dados aparentemente contraditórios.

Com relação à dimensão "ajustamento diádico (escore total)", percebeu-se um padrão semeIhante à dimensão "consenso", apresentando diferença estatisticamente significativa com as dimensões da escala de Satisfação Conjugal, ou seja, os respondentes que apresentaram médias mais altas em termos de ajustamento diádico encontravam-se na categoria de elevada Satisfação Conjugal, enquanto que aqueles que apresentaram médias mais baixas encontravam-se na categoria de baixa Satisfacão. Esse dado vai ao encontro do estudo de Landis, Peter-Wight, Mike e Guy (2013) que examinou a associação entre as estratégias de enfrentamento e a Satisfação Conjugal em casais mais velhos. Pôde-se constatar que tais estratégias, as quais são indicativos da adaptação ao estresse diário, estavam relacionadas à satisfação no casamento.

A Figura 2 apresenta a relação entre a Satisfacão Conjugal e a dimensão Ajustamento Diádico dos casais.

Figura 2: Porcentagem da dimensão ajustamento diádico total e a Satisfação Conjugal de casais $(c 2=54,752, g l=2, p<0,01)$.

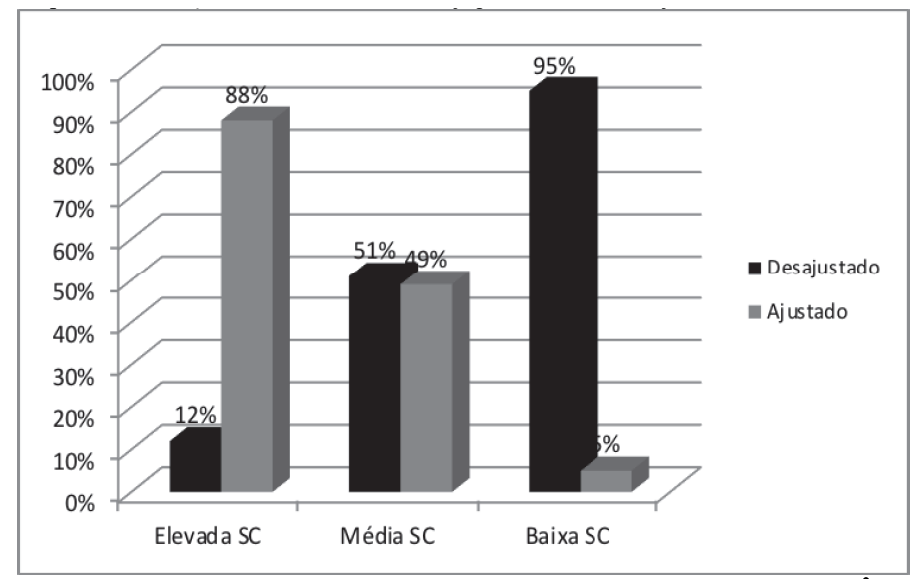

A Figura 2 apresenta um alto número de participantes em "sofrimento diádico" ou "desajustados" diadicamente que se encontram na categoria de baixa Satisfação. Isto mostra que o desajuste diádico ou o sofrimento nesta área afeta consideravelmente a Satisfação Conjugal e vice-versa.

A forma como cada parceiro participa do relacionamento (compartilhar sentimentos, diferenças, intimidade) pode estar associado a fatores relacionados à Satisfação Conjugal, bem como à própria vida (Scorsolini-Comin e Santos, 2011). Corroborando a afirmação dos autores, Rosado e Wagner 
(2015) afirmam que diferentes fatores podem contribuir ou prejudicar o bem-estar com a relação, dentre eles, nível da educação, tempo de duração da relação e idade dos cônjuges (Bertoni \& Bondenmann, 2010; Ghimire, 2013), a baixa autoestima, a insatisfação com o parceiro e problemas na comunicação (Bullard e cols., 2010; Morrisa, McMilland, Duncanc e Larson, 2011), o apoio emocional do cônjuge e a apreciação positiva da relação diádica (Lawrence e cols., 2008; Stapleton e cols., 2012). No caso do presente estudo estes fatores não foram determinados, indicando a necessidade de maior exploração nesta temática.

\section{CONSIDERAÇÕES FINAIS}

0 objetivo deste estudo foi investigar possíveis relações entre os Estilos PArentais percebidos, a Satisfação Conjugal e o Ajustamento Diádico. A partir dos dados apresentados é possível considerar a forte influência dos Estilos Parentais percebidos no ajustamento diádico, bem como na satisfação com o casamento. Além disso, as relações existentes entre a Satisfação Conjugal e 0 Ajustamento Diádico indicam como essas variáveis estão estreitamente relacionadas. É possível considerar também que os casais satisfeitos e ajustados são aqueles que apresentaram a habilidade para acordarem entre si, expressarem seus sentimentos e manterem um nível de coesão adequado.

As considerações mencionadas apontam para a necessidade de se pensar em estratégias de auxílio para casais em crise, bem como na relevância de se treinar habilidades relacionadas à melhora na relação conjugal, bem como trabalhar com prevenção no sentido de orientar pais em como suas práticas exercem influência no comportamento dos filhos enquanto crianças, adolescentes e na fase adulta.

Para pesquisas futuras sugere-se investigar a direção das variáveis relacionadas, por exemplo, se 0 ajustamento é que determina a satisfação ou se 0 contrário. Esse dado poderia favorecer 0 aprimoramento de intervenções com casais, bem como a maior variabilidade de religiões, uma vez que, neste estudo, a amostra de evangélicos está consideravelmente maior que na população de maneira geral, o que pode evidenciar um dado que não representativo da população brasileira.

\section{REFERÊNCIAS}

Baumrind (1966). Effects of authoritative control in child behavior. Child Development, 37, 888-907. Carneiro, R.S. \& Oliveira, M.G.C. (2013). Um estudo da relação entre estilos parentais e habilidades sociais. Revista Augustus, 18(36), 57-68.

Carvalho, M. S. D. P. \& Silva, B. M. B. (2014). Estilos parentais: um estudo de revisão bibliográfica. Revista Psicologia em Foco, 6(8), 22-42.

Costa, F.T., Teixeira, M.A.P. \& Gomes, W. B. (2000). Responsividade e Exigência: duas Escalas para Avaliar Estilos Parentais. Psicologia: Reflexão e Crítica, 13(3), 465-473.

Darling, N. (1999). Parenting Style and its correlates ERIC/EECe Publications - Digests.

Karwowski-Marques, A.P.M. (2008). Percepções sobre 0 amor, a qualidade e a satisfação com 0 relacionamento em casais. Dissertação de Mestrado. Programa de Pós-Graduação em Psicologia. Universidade do Vale do Rio dos Sinos. São Leopoldo, RS.

Lamborn, S.D., Mounts, N., Steinberg, L. \& Dornbusch, S. M. (1991). Patterns of competence and adjustment among adolescents from authoritative, authoritarian, indulgent, and neglectful. Child Development, 62, 1049-1065.

Landis, M., Peter-Wight, M., Martin, M. \& Bodenmann, G. (2013). Dyadic coping and marital satisfaction of older spouses in long-term marriage. GeroPsych: The Journal of Gerontopsychology and Geriatric Psychiatry, 26(1), 39-47. 


\section{ESTILOS PARENTAIS, SATISFAÇÃo CONJUGAL E AJUSTAMENTO DIÁDICO: UM ESTUDO EXPLORATÓRIO}

Maccoby, E. \& Martin, J. (1983). Socialization in the contexto of the Family: parent-child interaction. In: E.M. Hetherington \& P.H. Mussen (Orgs.), Handbook of the child psychology. Vol 4. Socialization, personality and the development (pp. 1-101). New York: Wiley.

Mendonça, S. \& Almeida, A.S.R. (2010). Vinculação aos pais e aos pares amorosos e comportamentos sexuais de jovens adultos. International Journal of Developmental and Educacional Psychology/INFAD, 2, 677-686.

Mondin, E.M.C. (2008), Práticas educativas parentais e seus efeitos na criação dos filhos. Psicologia Argumento, 26(54), 233-244.

Rosado, J.S. \& Wagner, A. (2015). Qualidade, ajustamento e satisfação conjugal: revisão sistemática da literatura. Pensando Famílias, 19(2), 21-33.

Sapienza, G., Aznar-Farias \& Silvares, E. F. M. (2009). Competência social e práticas educativas parentais em adolescentes com alto e baixo rendimento acadêmico. Psicologia: Reflexão $e$ Crítica, 22(2), 208-213.

Sardinha, A., Falcone, E.M.O. \& Ferreira, M. C. (2009). As relações entre a satisfação conjugal e as habilidades percebidas no cônjuge. Psicologia: Teoria e Pesquisa, 25(3), 395-402.

Scorsolini-Comin, F. \& Santos, M. A. (2011). Ajustamento diádico e satisfação conjugal: correlações entre os domínios de duas escalas de avaliação da conjugalidade. Psicologia: Reflexão e Crítica, 24(3), 439-447.

Scorsolini-Comin, F. \& Santos, M.A. (2011). Relações entre bem-estar subjetivo e satisfação conjugal na abordagem da psicologia positiva. Psicologia: Reflexão e Crítica, 24(4), 658-665.

Scorsolini-Comin, F. \& Santos, M.A. (2012). Ajustamento diádico e conjugalidade: avaliação do bem-estar no casamento. Journal of Human Growth and Development, 22(3), 367-372. 